\title{
Characterization of Inclusion Complexes Between Fluconazol and Different Cyclodextrin Derivatives
}

\author{
HAJ NAL KELEMEN ${ }^{1}$, GABRIEL HANCU1*, BERNADETTE MENTES ${ }^{1}$, IBOLYA FULO P², MELANIA CARCU DOBRIN¹, \\ DANIELA LUCIA MUNTEAN ${ }^{3,}$ ELEONORA MIRCIA ${ }^{4}$ \\ ${ }^{1}$ University of Medicine and Pharmacy from Tirgu Mures, Faculty of Pharmacy, Department of Pharmaceutical Chemistry, \\ 38 Gheorghe Marinescu, 540139, Tirgu Mures, Romania \\ ${ }^{2}$ University of Medicine and Pharmacy from Tîrgu Mures, Faculty of Pharmacy, Department of Toxicology and Biopharmacy, \\ 38 Gheorghe Marinescu, 540139, Tirgu Mures, Romania \\ ${ }^{3}$ University of Medicine and Pharmacy from Tirgu Mures, Faculty of Pharmacy, Department of Drug Analysis and Analytical \\ Chemistry, 38 Gheorghe Marinescu, 540139, Tirgu Mures, Romania \\ ${ }^{4}$ University of Medicine and Pharmacy from Tirgu Mures, Faculty of Pharmacy, Department of Pharmaceutical Industry and \\ Pharmaceutical Management, 38 Gheorghe Marinescu, 540139, Tirgu Mures, Romania
}

The aim of this study is to confirm the formation of inclusion complexes between fluconazoleand different cyclodextrin derivatives. Fluconazole is slightly soluble in water, but its solubility can be further increased by complexation with cyclodextrins. The binary systems between fluconazole and cyclodextrins were prepared in 1:1 molar ratios by physical-mixture method and kneading method. Differential scanning calorimetry (DSC), Fourier transformed-infrared spectroscopy (FT-IR) and molecular modeling methods were used to characterize solid state interactions between fluconazole and cyclodextrins in their binary systems. The analysis suggest the formation of a new solid phase, indicating a molecular interaction between the components. All binary systems showed superior dissolution profiles compared to pure fluconazole.

Keywords: fluconazole; cyclodextrins; differential scanning calorimetry; Fourier transform -infrared spectroscopy; solubility

Fluconazole (2-(2,4-difluorophenyl)-1,3-bis(1,2,4-triazol1-yl) propan-2-ol) (FCZ), is a first generation triazole derivative antifungal agent. The chemical structure of FCZ is presented in figure 1 .<smiles>OC(Cn1cncn1)(Cn1cncn1)c1ccc(F)cc1F</smiles>

Fig. 1.Chemical structure of FCZ

Structurally FCZ is a bis-triazole, the presence of two weakly basic triazole rings in the molecule conferring sufficient aqueous solubility to balance the lipophilicity of the 2,4-difluorophenyl group. FCZ has a water solubility of approximately $5.55 \mathrm{~g} / \mathrm{L}$ and an $\log P$ value of 0.41 , indicating its viability in both aqueous and lipophilic media. FCZ water solubility, makes it suitable for both oral and intravenous administration [1-3].

FCZ is strong and specific inhibitor of the sterol synthesis of fungi, by inhibiting cytochrome P450-mediated 14alpha-lanesterol demethylation, an essential step in biosynthesis of fungal ergosterol [3]. Administered both orally and intravenously, FCZ is active in a wide variety of fungal infections, its spectrum of activity including most Candida species, Cryptococcus neoformans, some dimorphic fungi and dermatophytes, among others $[1,4]$.

Its solubility in water can be further increased by complexation with CDs, which can enhance also the bioavailability of FCZ.

Cyclodextrins (CDs) are crystalline, nonhygroscopicwater-soluble cyclic oligosaccharides derived from starch, composed of $\alpha$-1,4-linked D-glucopyranose units; having a hydrophilic external surface and a hydrophobic internal cavity, in which they can incorporate different analytes through hydrophobic interactions. The most commonly used form of these ring-shaped molecules are $\alpha-, \beta-$, and $\gamma$-CDs formed by six, seven and eight glucose units, respectively (fig. 2) [5]. As a consequence of these features CDs can encapsulate a variety of hydrophobic molecules inside their cavity through non-covalent interactions to form inclusion complexes of host-guest type [6-8].

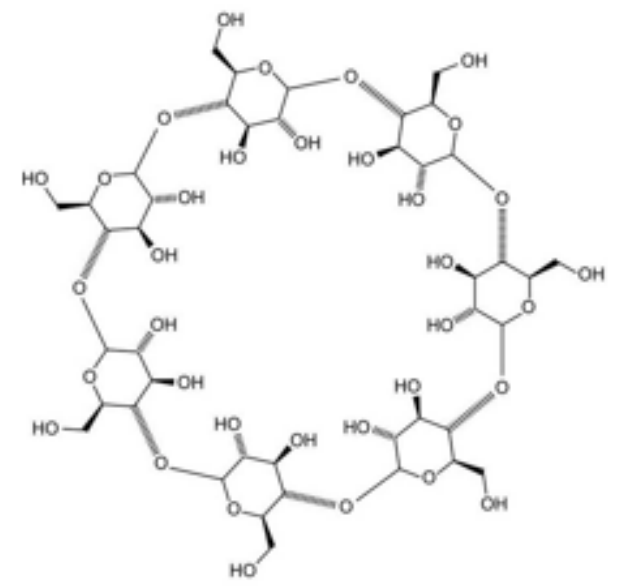

Fig. 2. Chemical structure of native $\beta-C D$

\footnotetext{
* email: gabriel.hancu@umftgm.ro
} 
solid phase were studied by solubility methods, spectroscopy (UV, IR), thermal analysis, and X-ray diffractometry, and their modes of interaction were assessed $[13,14]$.

NMR spectroscopic studies were published in order to evaluate the complexation of FCZ with $\beta-C D$, the results confirmed the formation of an inclusion complex in aqueous solution $[1,13,15]$. Complexes of FCZ an dbifonazole, miconazole, voriconazole prepared with different CDs by various methods such as kneading, coevaporation, physical mixing and spray-dried were characterized by FT-IR and DSC studies; the effect of complexation on the dissolution rate of azoles was studied [16-20].

The purpose of this study is to evaluate the possibility of interaction of FCZ through complexation with different types of CDs and the solubility increasing effect of different CD-derivatives. The binary systems between FCZ and different $C D$ s were prepared in one molar ratios 1:1 (FCZ:CD), using several methods (mixing, kneading). The resulted complexes were characterized by means of: thinlayer chromatography (TLC), thermal analyses differential scanning calorimetry (DSC), Fourier transformed infrared spectroscopy (FT-IR), and molecular modelling.

\section{Experimental part \\ Materials}

FCZ was kindly provided by VIM SPECTRUM td. (Corunca, Romania), while the CDs were purchased from Cyclolab Ltd. (Budapest, Hungary): native $\alpha-, \beta-, \gamma-C D$ and derivatized randomly-methylated- $\beta-C D$ (RAMEB) and hydroxypropyl- $\beta$-CD (HP- $\beta-C D)$ were used. All the chemicals were of analytical grade.

\section{Preparation of the binary systems}

Physical mixtures (PM): the components were mixed in a mortar and sieved through a $100 \mu \mathrm{m}$ sieve.

Kneaded products (KP): physical mixtures of FCZ and CDs derivatives were mixed with the same quantity of a $50 \%$ ethanolic solution. The obtained paste was kneaded until the bulk of the solvent had evaporated. After drying at room temperature and then in the oven at $105^{\circ} \mathrm{C}$, the KP were pulverized and sieved through a $100 \mu \mathrm{m}$ sieve.

These methods are simple and provide a high yield. The molecular ratio of the products were 1:1.

\section{Thin-layer chromatography (TLC)}

TLC has been successfully used for the analysis of $C D$ inclusion complexes. As a result of inclusion complexation, the Rf value for stable complexes should be lower than Rf values of the active substances.

The TLC system consisted of: CamagLinomat IV semiautomatic sampler (Camag, Switzerland), Camag Normal Development Chamber, Camag UV fluorescence inspection lamp (Camag, Switzerland). As stationary phase we used $20 \times 20 \mathrm{~cm}$ pre-coated silicagel $\mathrm{GF}_{254}$ HPTLC glass plates (Merck, Germany).

The mobile phase was toluene-chloroform-methanol 1.2:3.0:0.4 (v/v) [24]. Sample of 5 $\mu \mathrm{L}$ were applied on the chromatographic plate. The plates were developed over a distance of $15 \mathrm{~cm}$, dried in a stream of hot air, and examined first under UV radiation at $254 \mathrm{~nm}$ wavelength, finally the plate was sprayed with iodine solution.

\section{Differential scanning calorimetry (DSC)}

The temperature and enthalpy measurements were performed using a Mettler Toledo DSC 823e Thermal Analysis system (Schwerzenbach, Switzerland).
Approximately $1-2 \mathrm{mg}$ of the active material or binary systems were examined in aluminium pans betw een 25 $400^{\circ} \mathrm{C}$ in a nitrogen atmosphere (flow rate of $50 \mathrm{~mL} / \mathrm{min}$.). The heating rate was $10^{\circ} \mathrm{C} / \mathrm{min}$.

\section{Fourier-transformed - infrared spectroscopy (FT-IR)}

FT-IR analysis provide the detection of inclusion complexation in terms of diffraction and IR spectra patterns of the complex which must be clearly distinct from that resulting by the superimposition of individual diffraction and IR spectra. The IR spectra of FCZ, CD derivatives and their binary systems were recorded using a FT-IR 470 Plus, (Ablej asco, Japan) spectrometer. The resolution was 4 $\mathrm{cm}^{-1}$, the wave number range was $2000-400 \mathrm{~cm}^{-1}$ and the scan number was 64 . The samples were included in $\mathrm{KBr}$ pellets. Analyses were performed at room temperature.

\section{Molecular modelling studies}

Molecular modelling studies were performed using the Hyperchem 8.0 software. In order to find the most stable conformation of the complexes, molecular mechanics simulations were applied. Energy minimization was performed using the force field method with the PolakRibiere algorithm ( $0.01 \mathrm{kcal} / \mathrm{moleA}$ gradient). The initial distance between the host and guest molecule was set at about $5 \AA$; the energy minimization of the complex was conducted until the conformation with the lowest energy was found. The binding energy ( $\mathrm{E}_{\text {bond }}$ ) was calculated using the formula (eq. 1):

$$
E_{\text {bond }}=\left(E_{F L C}+E_{C D}\right)-E_{\text {compl }}
$$

where $E_{F L C}$ and $E_{C D}$ are the energy of the guest and host molecules and $E_{\text {compl }}$ shows the energy of the complex after energy minimization.

\section{Dissolution studies}

In vitro dissolution studies of FCZ (SR 8-PLUS HansonResearch, USA), physical mixtures and kneaded products complexes were performed by adding the solid systems, equivalent to $10 \mathrm{mg}$ of $\mathrm{FCZ}$, to a $900 \mathrm{~mL}$ phosphate buffer at $\mathrm{pH} 7.0$ thermostated at $37 \pm 0.5^{\circ} \mathrm{C}$, and stirred at 100 $\mathrm{rpm}$. At fixed time intervals, samples were withdrawn with a filter-syringe $(0.45 \mu \mathrm{m})$ and assayed spectrophotometrically using a UV-Vis spectrophotometer (Shimadzu UV-1601, J apan) at $261 \mathrm{~nm}$. The volume of the dissolution media was kept constant during the experiment.

\section{Results and discussions}

Thin-layer chromatography (TLC)

The chromatograms of $F C Z, C D$, in situ $C D-F C Z$ mixtures and binary complexes of FCZ with $\beta-C D, H P-\beta$ CD and RAMEB prepared by physical mixing and kneading are presented in figure $3 a$, figure $3 b$ and figure $3 c$ respectively.

Examined in UV light, the chromatograms exhibits a fluorescent spot in case of $F C Z$, with a Rf of 0.25 , while for the $C D$ derivatives there isn't any fluorescence spot noticed on the plate. When pulverized with iodine solution, the CDs are revealed as a yellow citrine spots on the start line and no reaction appears for FCZ. For the in situ mixture, two spots can be seen, one for FCZ and one at the start line for the $C D$, visible only after applying the iodine solution. In case of the products obtained by physical-mixture and kneading methods, only one intensely fluorescent spot appears in UV light which turns yellow citrine when pulverized with iodine solution.

The results obtained with the in situ mixture acts, exclude the possibility of complex formation on the chromatographic plate, while in the case of binary products 

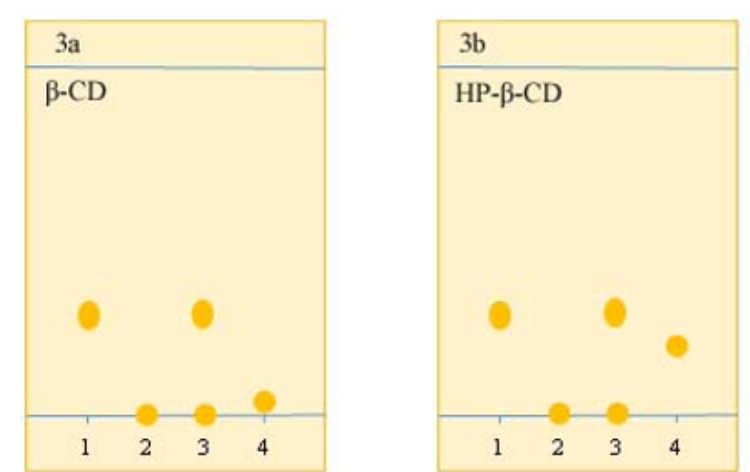

the complexes have a different chromatographic behaviour that the active substances, the Rf value of complexes being smaller than that of the guest molecule.

\section{Differential scanning calorimetry (DSC)}

Differences in the thermal behaviour of $F C Z, C D s$, and the corresponding inclusion complexes were evident. As shown in figure 4, FCZ exhibits a characteristic endothermic fusion peak at $141.73^{\circ} \mathrm{C}$ corresponding to the FCZ melting point. Furthermore, $\alpha-, \beta-, \gamma-C D, H P-\beta-C D$ and RAMEB show broad endothermic events in the range from 30 to $95^{\circ} \mathrm{C}$, which are related to the loss of adsorbed water, and small endo- or exo- effects at $210-325^{\circ} \mathrm{C}$ due to thermal

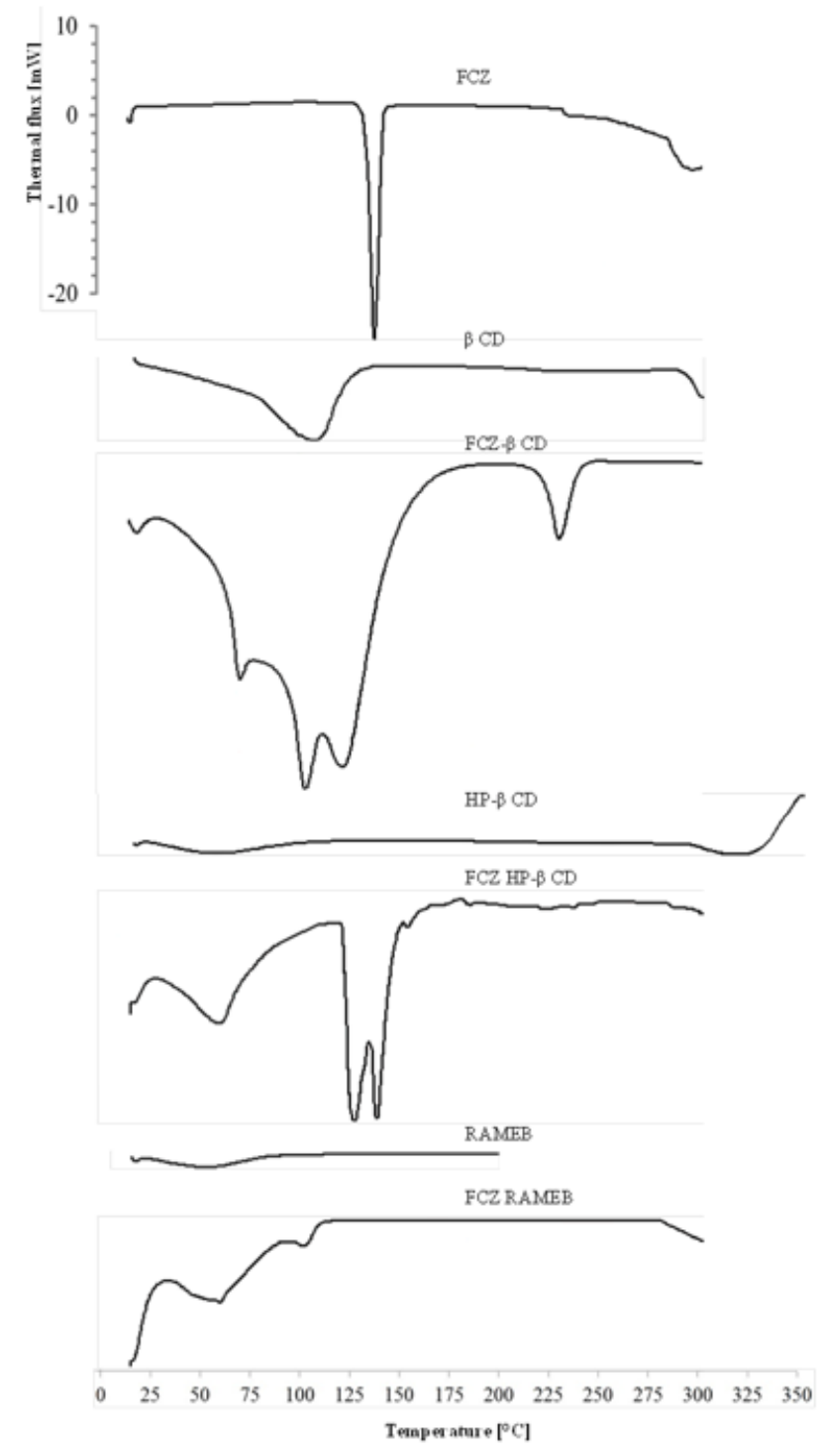

Fig. 4. DSC thermograms of FCZ, CDs, and complexes

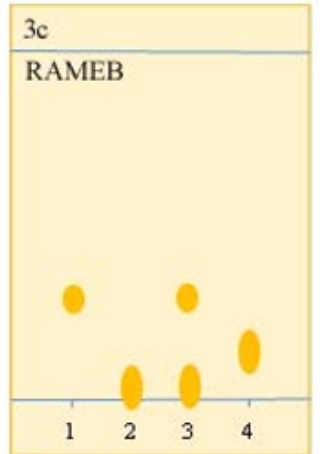

Fig. 3a, 3b, 3c TLC of FCZ, CDs, and complexes (spot 1. 0.5\% FCZ in ethanol, spot 2. $0.5 \% \mathrm{CD}$ in distilled water, spot 3. in situ mixture of FCZ and CD solution, spot 4. $0.5 \%$ water solutions of the products obtained by physical-mixture methods and kneading method)

degradation. DSC thermograms of the physical mixture for FCZ and $\alpha-, \beta$ and $\gamma-C D, H P-\beta-C D$ and RAMEB show the existence of the endothermic peak of FCZ indicating interactions between the CDs and FCZ. The FCZ peak in the physical mixture with $C D$ s decreases, indicating a more intense interaction of FCZ with CDs. This endothermic peak is still present in kneading products, as FCZ- $\beta-C D$ and FCZ- $\gamma$-CD complexes, show an endothermic peak at $131,21^{\circ} \mathrm{C}-133,35$, whereas there is a new endothermic peak in the range of $140-160 \mathrm{C}$ that possibly shows complex formation.

In the binary systems of FCZ-RAMEB and FCZ-HP- $\beta$-CD we observed the disappearance of the $F C Z$ endothermic peak, indicating a more intense interaction of $\mathrm{FCZ}$ with RAMEB andHP- $\beta$-CD. The FCZ peak in the kneading products increases at $152,2-158,9^{\circ} \mathrm{C}$ indicating a more intense interaction of FCZ with the CDs.

The absence of the characteristic peak of the analyte is a strong evidence of the inclusion of the analyte into the CD cavity. This could be attributed to the formation of an amorphous solid dispersion, molecular encapsulation of the analyte into the CD cavity, or both.

\section{Fourier-transformed - infrared spectroscopy (FT-IR)}

In order to investigate the vibrational changes upon hostguestinteractionbetween FCZ and CDs, FTIR spectroscopy was used. FTIR technique is useful to identify which is the vibrational mode of the analyte and suggesting the interactions between these molecules in solid state [25].

The FT-IR spectra of FCZ (fig.5a) reveal numerous absorption bands in the fingerprint region. The FTIR spectrum of FCZ exhibits characteristic peaks at $3071 \mathrm{~cm}^{-}$ lattributed to the $\mathrm{C}-\mathrm{H}$ stretching aromatic ring, $3117 \mathrm{~cm}^{-1}$ due to stretching triazole ring, $3408 \mathrm{~cm}^{-1}$ due to $-\mathrm{NH}$ stretching, $3063 \mathrm{~cm}^{-1}$ due to $\mathrm{C}-\mathrm{H}$ stretching, $1584 \mathrm{~cm}^{-1}$ due to $\mathrm{C}-\mathrm{N} \mathrm{cm} \mathrm{cm}^{-1}$ stretching, $1619 \mathrm{~cm}^{-1}$ due to $\mathrm{C}=\mathrm{C}$ stretching aromatic ring, $1506 \mathrm{~cm}^{-1}$ due to triazole ring stretching, $1419 \mathrm{~cm}^{-1}$ due to triazole ring stretching, $1105 \mathrm{~cm}^{-1}$ due to $\mathrm{C}-\mathrm{F}$ stretching and $1085 \mathrm{~cm}^{-1}$ due to $\mathrm{C}-\mathrm{OH}$ stretching.

A broad IR band centred at $3190 \mathrm{~cm}^{-1}$ is attributed to the hydrogen bonded $-\mathrm{OH}$ stretching mode of the tertiary alcohol group. The three weak IR absorption maxima at 1898,1844 and $1766 \mathrm{~cm}^{-1}$ are characteristic of a 1,2,4trisubstituted benzene ring.

The FT-IR spectra of $\beta-C D$ (fig.5b) reveal numerous absorption bands in the fingerprint region. In the spectrum of $\beta$-CD there is a wide absorption band in the 1200-1000 $\mathrm{cm}^{-1}$ area, attributed to the glucopyranosic ring. Another broad and strong absorption band in the $3000 \mathrm{~cm}^{-1}$ domain is attributed to $-\mathrm{OH}$ stretching. For the binary systems, the $1600-600 \mathrm{~cm}^{-1}$ domain was chosen to highlight the modification of spectra due to complexation, CDs mask the characteristic peaks of groups that are included in their cavity.

Between the complexed drug and the IR spectrum of FCZ there is a significant difference between the number 

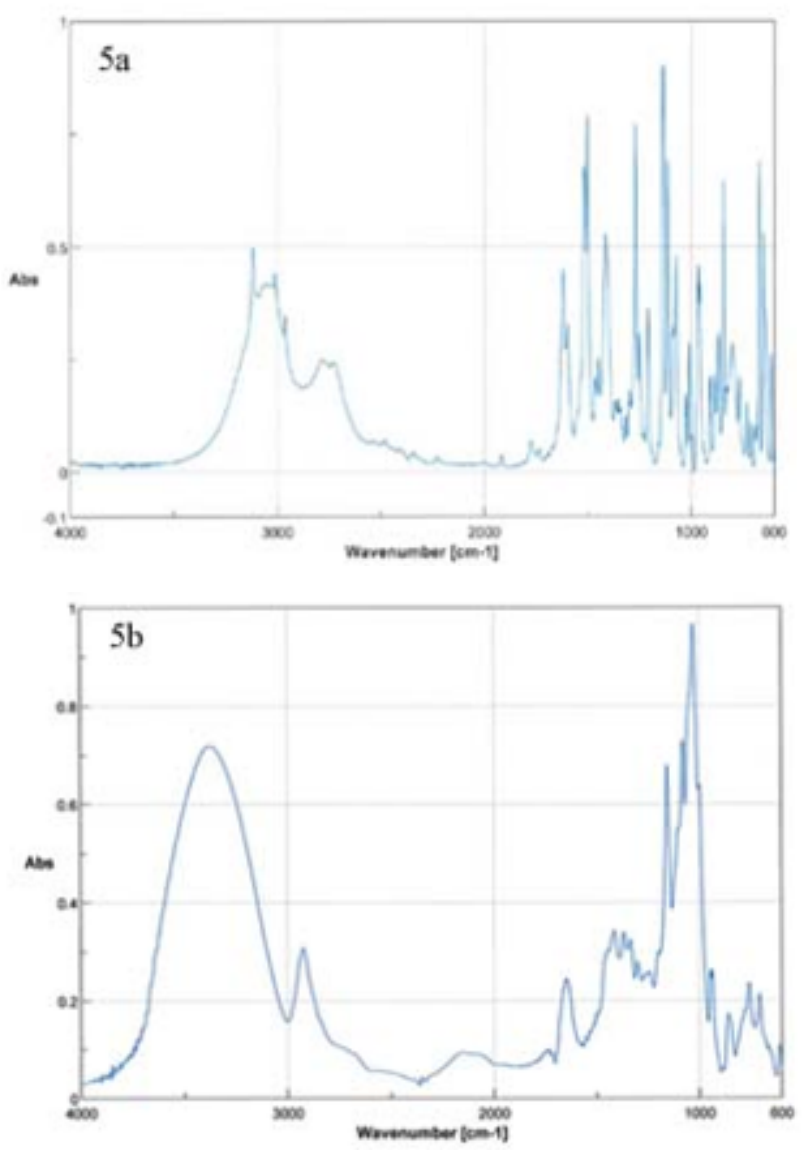

Fig. 5 FT-IR spectra of FCZ (5a) and $\beta-C D(5 b)$

and location of the peaks. The $3117 \mathrm{~cm}^{-1}$ peak characteristic of the triazole ring of FCZ disappears, suggesting a covalent, strong interaction between the guest and the host molecules.

The absorption spectrum of the complex of FCZ with $\beta$ $C D$ shows that the absorption bands of primary and secondary $-\mathrm{OH}$ groups flanking the narrower and wider rims of CD do not appear or shift in the complex. This may indicate that the free deformation of these groups is somew hat hindered in the complex. The absorption band around $3280 \mathrm{~cm}^{-1} \mathrm{is}$, according to literature data, the range of water vibrations. The fact that this band appears only in the case of pure CD suggestsindirectly that the molecule entering the cavity during the complex formation displaces the previously contained water molecules in the cavity. The disappearance of characteristic frequencies of imidazole ring from the absorption spectra of the complexes in range of $1000-650 \mathrm{~cm}^{-1}$ indicates that FCZ fittedthe CDcavity. Together with the imidazole ring the aliphatic carbon atom bonded to $\mathrm{N}$ of the imidazole was also encapsulated (fig. 6).

Changes in infrared spectra such as the disappearance or intensity of characteristic bands, the emergence of new bands, demonstrate the interaction between FCZ and CDs. From the spectra it appears that the strongest interaction with RAMEB followed by HP- $\beta-C D$.

\section{Molecular modelling studies}

Spatial arrangement of the inclusion complexes (front view and side view) are shown in figure 7 According to eq. 1 the highest value of energy difference indicates the most stable complex; in this context the RAMEB-FCZ complex shows the highest binding energy.

The increasing order of the binding energies is: $\beta-C D$ (1.23 kcal/mole) < HP- $\beta$-CD (9.88 kcal/mole) < RAMEB

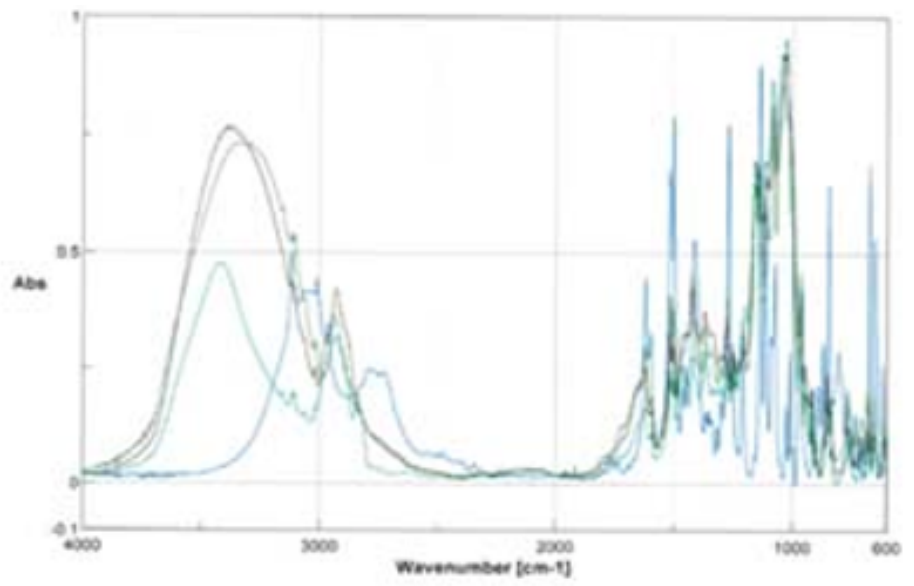

Fig.6. FT-IR spectra of FCZ KP complexes with $\beta-C D, H P-\beta-C D$, RAMEB (FCZ - blue, $\beta$-CD - green, HP- $\beta$-CD - red, RAMEB - light green)

( $15.36 \mathrm{kcal} / \mathrm{mole})$. In the case of complexes of $\beta-C D$ and RAMEB a complete inclusion of the FCZ can be observed; complexation with HP- $\beta-C D$ involves encapsulation of one of the triazole groups in the $C D$ cavity.

\section{Dissolution studies}

CDs play a very important role in formulation of poorly water soluble drugs by improving the apparent drug solubility and dissolution through inclusion complexation or solid dispersion.
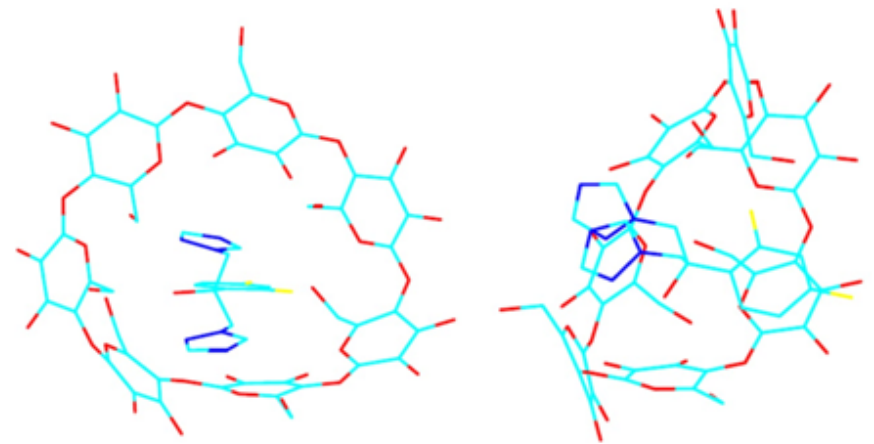

Beta-CD - Front view

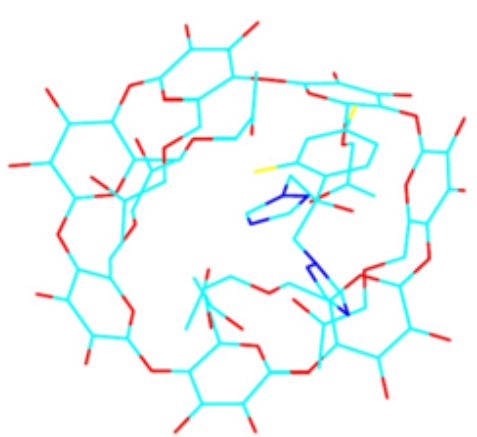

Beta $\mathrm{CD}$ - side view

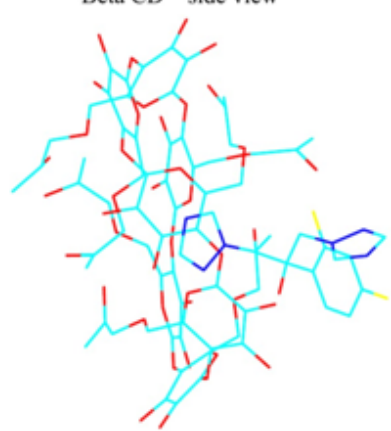

HP- $\beta$-CD - front view

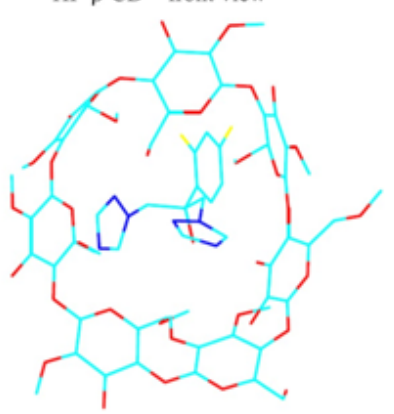

RAMEB - front view

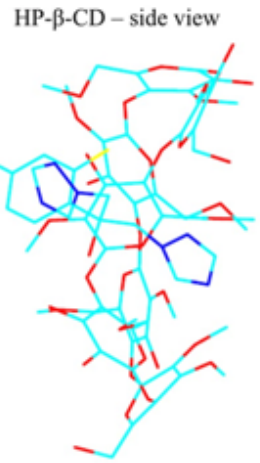

RAMEB - side view
Fig. 7.The spatial arrangement of the complexes 

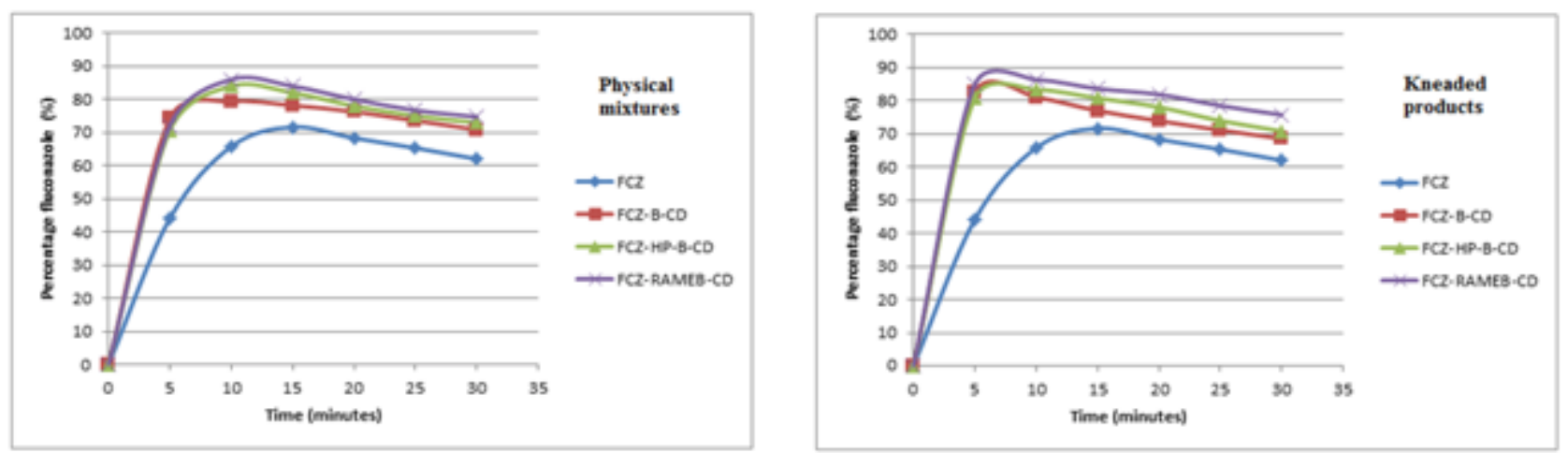

FIg. 8. Comparative dissolution protile of $\mathrm{rC} \angle$ and the products of CDS

Comparing the dissolution profile of $\mathrm{FCZ}$ with the release curves of complexes with CDs, it can also be observed that the kneaded products dissolve faster and the amount of dissolved material is higher, which suggests that the inclusion complex formation is better for a kneaded product.

The increase in the dissolution profiles depend on the nature of the $C D$ derivative, the $F C Z$ concentration in the products and on the processing method. The various $C D$ derivatives increased the solubility of $F C Z$ to different extents, RAMEB proving to be the most effective CD derivative for the complexation.

\section{Conclusions}

In TLC there was a significant diminution of the Rf values of the complexes compared with the active substances which can be interpreted as the formation of inclusion complexes. DSC analysis sustains the hypothesis of partial inclusion complexes formation between FCZ and CDs. The thermo behaviour depends both on the preparation method used and the composition of the product. Changes in IR spectra such as the disappearance or change in intensity of characteristic bands, the emergence of new bands, demonstrate the interaction between FCZ and CDs. The increase in the dissolution characteristics depend on the nature of the $C D$ derivative, on the processing method. The various $C D$ derivatives increased the solubility of $F C Z$ to different extents.

Acknowledgments: This work was supported by Research Grants by the University of Medicine and Pharmacy of TârguMureo, Romania (grant contractfor execution of research projects nr.10228/20.07.2016).

\section{References}

1.ORGOVAN, G., KELEMEN, H., NOSZAL, B., J ournal of Inclusion Phenomena and Macrocyclic Chemistry, 84, nr.(3-4), 2016, p. 189-196.
2.CORREA, J.C.R., SALGADO, H.R.N., Review of Analytical Chemistry,.41,2011, p.124-132.

3.BERG, D., BUCHEL, K.H., PLEMPEL, P., REgEL E., Trends in Pharmacology Sciences,7, 1986, p. 233 - 238.

4.LEE, W., LEE, D.G., Microbiology, 164, 2018, p.194-204.

5.SZEJ TLI, J., Chemistry Reviews., 98, nr.5, 1998, p. 1743.

6.LOFTSSON, T.,DUCHENE, D., International J ournal of Pharmaceutics, 329, 2007, p.1-11.

7.MURA, P.J., Journal of Pharmaceutical and Biomedical Analysis,113,2015, p.226-238.

8.YURTDAS, G., DEMIREL, M., GENC., L., J ournal of Inclusion Phenomena and Macrocyclic Chemistry,70, nr.(3-4), 2011, p. 429-435. 9.TRANDAFIRESCU, C., GYERESI , AA., SZABADAl, Z., KATA, M., AIGNER, Z., Farmacia,62, nr. 3,2014, p. 513-523.

10.MURA, P., MAESTRELLI, F., CIRRI, M., FURLANETTO, S., PINZAUTI, S., J ournal of Thermal Analysis and Calorimetry,73, nr. 2, 2003, p. 635646.

11.MARCINIEC, B., KOZAK, M., DETTLAFF, K., Journal of Thermal Analysis and Calorimetry, 77, nr. 1, 2004, p.305-317.

12.DESAI, S.R., SHAIKH, M.M, DHARWADKAR, S.R., Thermochimica Acta,399, nr. 1-2, 2003, p.81-89.

13.LI, J., ZHANG, S., ZHOU, Z., GUAN, S., ZHANG, L., J ournal of Inclusion Phenomena andMacrocyclic Chemistry,84, nr.(3-4), 2017, p.209-217.

14.HAJNAL, K., HANCU, G., MUNTEAN, D.L., CUSU, JP., Rev. Chim. (Bucharest), 67, no.10, 2016, p. 2065-2070.

15.UPADHYAY, S.K., KUMAR, G.,Chemistry Central Journal,3, nr. 1, 2009, p.9.

16.KELEMEN, H., CSILLAG, A., HANCU, G., et al. Macedonian J ournal of Chemistry and Chemical Engineering, 36, nr. 1, 2017, p. 81-91.

17.TRANDAFIRESCU, C., AVRAM, S., SOICA, C., ARPAD, GY., KATA, M., DEHELEAN, C., SZABADAI, Z., BORCAN, F., Rev. Chim. (Bucharest), 65, no. 11,2014, p.1336-1339.

18.ALKHAMIS, K.A., OBAIDAT, A., NUSEIRAT, A. F.,Pharmaceutical Development and Technology, 7, nr. 4, 2004, p. 491-503.

19.MILETIC, T., KYRIAKOS, K., GRAOVAC, A., IBRIC, S., Carbohydrate polymers,9, nr. 1, 2013, p.122-131.

20.KELEMEN, H., Farmacia, 52, nr. 2, 2004, p. 88-93.

Manuscript received: 18.09 .2018 